with its maximum at $565 \mathrm{~m} \mu$ accompanying the free radical formation for a number of flavin enzymes. Ehrenberg and Ludwig ${ }^{8}$ reported the shift of the maximum peak of the old yellow enzyme about $10 \mathrm{~m} \mu$ toward longer wavelengths (465-475 $\mathrm{m} \mu)$ accompanying free radical formation.

The difference between the result reported here and those reported by other workers may be attributed to the difference between the enzyme samples or some other reason.

\section{Kunio Yagi}

TAKAYUKI OzAWA

Institute of Biochemistry,

Faculty of Medicine,

University of Nagoya,

Nagoya, Japan.

${ }^{1}$ Yagi, K., and Ozawa, 'T., Biochim. Biophys. Acta, 60, 200 (1962).

2 Yagi, K., and Ozawa, T., Biochim. Biophys. Acta (in the press).

${ }^{3}$ Yagi, K., and Ozawa, T., Biochim. Biophys. Acta, 67, 685 (1963).

4 Yagi, K., and Ozawa, T., Biochim. Biophys. Acta, 56, 420 (1962).

'Yagi, K., and Ozawa, T., Biochem. $Z$., (in the press).

6 Beinert, H., Biochim. Biophys. Acta, 20, 588 (1956).

7 Beinert, H., J. Biol. Chem., 225, 465 (1957).

${ }^{8}$ Ehrenberg, A., and Ludwig, G. D., Science, 127, 1177 (1958).

\section{Metabolism of 2,4-Dichlorophenoxyacetic Acid ('2,4-D') by Aspergillus niger van Tiegh}

EARLIER papers dealing with the microbial degradation of 2,4-dichlorophenoxyacetic acid $(2,4$-D) have indicated that fission may be the ultimate fate of the aromatic ring. Thus Rogoff and Reid ${ }^{1}$ detected an almost quantitative production of chloride ion by an organism belonging to the genus Corynebacterium, isolated from soil, while Fernley and Evans ${ }^{2}$ obtained $\alpha$-chloromuconic acid as a metabolite using a soil Pseudomonas sp., although under certain conditions the latter workers found 2,4-dichlorophenol to be the main product.

By contrast, previous investigations of the metabolism of aryloxyacetic acids by fungi $i^{3-5}$ have shown that the most notable feature was the predominance of apparently non-specific nuclear hydroxylation, without ring fission. The metabolism of 2,4-dichlorophenoxyacetic acid, using a replacement culture technique with Aspergillus niger, has proved different, however, in that not all vacant ring sites are hydroxylated. The major metabolite has been identified as 2,4-dichloro-5-hydroxyphenoxyacetic acid, but two very minor metabolites have been shown to be non-identical with the corresponding 3-or 6-hydroxy acids, the production of which might have been expected in the light of earlier work ${ }^{4}$. These compounds have been separated with some difficulty by partition chromatography using silica gel as the supporting medium for the stationary aqueous phase which was buffered to $p \mathrm{H} 10$, the mobile phase being 50 per cent saturated aqueous chloroform $/ n$-butanol $(60: 40)$.

One compound has now been identified by comparison of infra-red absorption spectra and mixed m.p. as the hitherto unknown 2,5-dichloro-4-hydroxyphenoxyacetic acid, an authentic specimen of which was prepared from 2,5 -dichlorohydroquirone. The formation of this hydroxy acid from 2,4-D is novel in that it involves not only hydroxyl-chlorine replacemont (as was found with 2chlorophenoxyacetic acid ${ }^{4}$ ) but also a chlorine shift. This is reminiscent of the formation of homogentisic acid from tyrosine by $A$. niger and various Penicillium sp. ${ }^{6}$, though in that case it is likely that the side-chain migratos.

2,5-Dichloro-4-hydroxyphenoxyacetic acid is also the sole acidic metabolite produced by $A$. niger from 2,5dichlorophenoxyacetic acid, but careful scrutiny of the 2,4-dichlorophenol used to prepare the 2,4-D for use in metabolism investigations has not revealed any 2,5dichlorophenol impurity. Morcover, 2,4-D recovered from the silica-gel column separation, when re-used in the replacement culture technique, resulted in further produc- tion of 2,5-dichloro-4-hydroxyphenoxyacetic acid. Final proof of the genesis of 2,5-dichloro-4-hydroxyphenoxyacetic acid was provided by the use of 2,4-D labelled with carbon-14 in the carboxyl group. Metabolism of this acid by $A$. niger gave a radiosctive chromatogrephic spot with the same $R_{F}$ value.

Thus the bona fide production of 2,5-dichloro-4-hydroxy. phenoxyacetic acid from 2,4-D seems certain and the question remains whether its formation is in any way involved in the mechanism of formation of the major metabolite. This appears to be unlikely in view of the fact that no corresponding 4-hydroxy compound is formed in the metabolism of 4-chloro-2-methylphenoxyacetic acid ('MCPA') by $A$. niger, where the previously unkrown 4-chloro-5-hydroxy-2-methylphenoxyacetic acid has been identified as the major metabolite.

\section{J. K. FAULKNer \\ D. WoODCOCK \\ Research Station, University of Bristol, Long Ashton, Bristol.}

${ }^{1}$ Rogoff, M. H., and Reid, J. J., J. Bact., 71, 303 (1956).

${ }^{2}$ Fernley, H. N., and Evans, W. C., Biochem. J., 73, 22P (1959).

${ }^{3}$ Byrde, R. J. W., and Woodeock, D., Biochem. J., 65, 682 (1957)

4 Faulkner, J. K., and Woodcock, D., J. Chem. Soc., 5397 (1961).

${ }^{5}$ Clifford, D. R., and Woodcock, D., Nature, 203, 763 (1964).

'Utkin, L. M., Biokhimiya, 15, 330 (1950).

\section{Utilization of Labelled 'Myleran' for the Determination of the Size of DNA Molecules in Cells}

THE mutagenic action of tho electrophilic alkylating agents has been attributed to many different causes. For Alexander and Stacey $^{1}$, the alkylation of the DNA phosphates could be sufficient to induce mutations; but these could also be the consequence of the hydrolysis of the very unstable triester phosphate formed, with rupture of the macromolecule followed by large deletions. Lawley and Brookes ${ }^{2}$ have postulated that the 7-alkylation of guanine makes this base couple with thymine instead of cytosine and so is responsible for transitions. But the alkylation of the guanine and adenine residues can also be followed by the loss of the alkylated base ${ }^{3}$; this depurination might act in two ways: the hole left gives the opportunity for transitions, transversions or nucleotide deletions when the DNA replicates, or the DNA sugarphosphate 'backbone' can break with loss of a part of the chain. All these chemical mechanisms damage only one helix of the DNA molecule exposed to the mono- or bi-functional alkylating drug and the mutation ought to appear only in one half of the genomes of the following generations.

Bridge formation between the two helices by a bifunctional alkylating agent would prevent the DNA replication and lead to the deletion of the cross-linked macromolecule which will have no descent in any genome of the following generations ${ }^{4}$. Besides this qualitative difference, mutation following bridge formation must be quantitatively the most important for bifunctional alkylating agents because the target for the drug is then the whole DNA molecule carrying the competent gene instead of a few sensitive triplets inside this gene.

In a previous publication ${ }^{4}$, we tried to evaluate the size of a DNA molecule carrying a known genetic locus by the use of a bifunctional alkylating reagent labelled in its alkyl moiety. Cells of Chlamydomonas eugametos Moevus, sex minus, haploid and spontaneously resistant to streptomycin, were treated with 'Myleran' (1,4-dimethanesulphonyloxybutane) labelled with tritium in the butanediol moiety and a correlation was found between the frequency of cells becoming sensitive to streptomycin and the radioactivity of the isolated DNA. Starting from the hypothesis mentioned earlier that, when the mutation reaches all the cells jssued from the treated one, the chemical damage must be a cross-linking between the 